\title{
A prevalência de lesões musculoesqueléticas em funcionários de empresas de funilaria automotiva em Teresina-PI
}

\author{
The prevalence of musculoskeletal injuries in employees of \\ automotive functional companies in Teresina-PI
}

\author{
Rivanda Berenice Silva de Freitas Adad' ${ }^{1}$, Danyele Holanda da Silva ${ }^{2}$, Izabelle Macedo de Sousa ${ }^{3}$ \\ ${ }^{1}$ Autora para correspondência. Centro Universitário Maurício de Nassau. Teresina, Piauí, Brasil. ORCID: 0000-0002-2828-6464. rivandaadad@gmail.com \\ ${ }^{2}$ Centro Universitário Maurício de Nassau. Teresina, Piauí, Brasil. ORCID: 0000-0001-7517-5890. dan_sil_holanda@hotmail.com \\ ${ }^{3}$ Centro Universitário Maurício de Nassau. Teresina, Piauí, Brasil. ORCID: 0000-0003-1406-0365. izabelle_macedo@hotmail.com
}

\begin{abstract}
RESUMO | INTRODUÇÃO: Os distúrbios osteomusculares relacionados ao trabalho são um conjunto de afecções comumente ligadas ao trabalho e podem ocorrer de forma combinada ou não ao uso repetido e forçado de grupos musculares e à manutenção de posturas inadequadas. Sua incidência vem aumentando gradativamente a cada ano, devido à influência de diversos fatores. OBJETIVOS: Identificar a prevalência de lesões musculoesqueléticas em funcionários de empresas automotivas. METODOLOGIA: Este estudo foi do quantitativo e qualitativo. Participaram da pesquisa 23 voluntários, os quais foram analisados por meio de uma avaliação física e socioeconômica, além de ser aplicado o Questionário Nórdico de Sintomas Osteomusculares. Os participantes foram observados durante a execução de suas atividades no seu ambiente de trabalho, onde foram analisadas as manutenções e compensações posturais e os principais movimentos durante as atividades. RESULTADOS: O estudo evidenciou dentre os participantes predomínio do sexo masculino, foi apresentada a distribuição da amostra em relação a faixa etária, escolaridade, tempo de serviço, função que exerce, percepção de esforço, além de relatar a existência de dor durante e/ou após ao horário de trabalho. CONCLUSÃo: Os resultados apontaram para a região da coluna lombar como sendo a de maior intensidade de distúrbios musculoesqueléticos relacionados ao trabalho entre o grupo de trabalhadores pesquisados. Foi observado que não há uma relação linear entre sintomas osteomusculares, avaliação hemodinâmica, idade e tempo de serviço. Por outro lado, a baixa escolarização esteve associada com o aumento da probabilidade de diagnóstico.
\end{abstract}

PALAVRAS-CHAVE: DORT. Epidemiologia. Saúde do trabalhador. Qualidade de vida. Lesões ocupacionais.
ABSTRACT | INTRODUCTION: Work-related musculoskeletal disorders are a set of common conditions that can affect the combined form or not use repeated and forced repeated and forced muscle groups and the maintenance of inappropriate postures. Its incidence gradually arrives each year, due to the influence of several factors. OBJECTIVES: To identify the prevalence of musculoskeletal injuries in employees of automotive companies. METHODOLOGY: This study was quantitative and qualitative. 23 volunteers participated in the research, which were analyzed by means of a physical and socioeconomic evaluation, in addition to being applied or the Nordic Musculoskeletal Questionnaire. Participants were observed during the performance of their activities in their work environment, where they were analyzed as postural maintenance and compensation and the main movements during activities. RESULTS: The study showed among the participants with a predominance of male gender, who received a distribution of the sample in relation to age group, education, length of service, functions they exercise, perception of effort, in addition to relating a variable of pain during and/or after working hours. CONCLUSION: The results pointed to a region of the lumbar spine as being the highest intensity of work-related skeletal muscle disorders among the group of workers surveyed. It was observed that there is no linear relationship between musculoskeletal symptoms, hemodynamic assessment, age and length of service. On the other hand, low schooling was associated with an increased probability of diagnosis.

KEYWORDS: WMSD. Epidemiology. Worker's health. Quality of life. Occupational Injuries. 


\section{Introdução}

Os distúrbios musculoesqueléticos são considerados um grave problema de saúde pública, o que causa um impacto relevante na qualidade de vida e uma carga econômica considerável nos custos de compensação de um país como perda de proventos e produtividade. Estudos descrevem uma relação entre demandas físicas no trabalho e distúrbios musculoesqueléticos, porém demandas psicossociais também foram apontadas como possíveis fatores de risco'1.

Os distúrbios osteomusculares relacionados ao trabalho (DORT) são um conjunto de afecções que atingem tendões, músculos, nervos, fáscias, sinóvias e ligamentos de forma separada ou associada, podendo ocorrer ou não a degeneração dos tecidos afetando principalmente os membros superiores, região escapular, pescoço e coluna lombar. Estas disfunções são comumente ligadas ao trabalho e podem ocorrer de forma combinada ou não ao uso repetido e forçado de grupos musculares e a manutenção de posturas inadequadas ${ }^{2}$.

Segundo os registros do SINAN (Sistema de Informação de Agravos de Notificação), os diagnósticos específicos mais comumente relatados foram as afecções de ombro, as dorsalgias e os transtornos das sinóvias, dos tendões e dos discos vertebrais. A incidência de casos de DORT vem aumentando gradativamente a cada ano devido à influência de diversos fatores. Esse fato pode ser explicado pela nova estrutura organizacional adotada pelas empresas, que as mesmas priorizam a produtividade e lucro, em detrimento aos limites físicos e psicossociais de seus colaboradores. Locais de trabalho inadequado, equipamentos sem os devidos ajustes, postura mantida por tempo prolongado, ausência de intervalos, movimentos repetitivos, isso reflete desfavoravelmente na saúde do trabalhador ${ }^{3}$.

A instabilidade da saúde entre trabalhadores ocasiona o aumento de faltas no trabalho, além de aumentar também o risco de afastamento médico. Portanto, incentivar a promoção da saúde e o bem-estar no ambiente de trabalho, poderá ser decisivo para atenuar as ausências ou saídas prematuras por motivo patológico e garantir um aumento de retorno financeiro para a empresa ${ }^{4}$.
A LER/DORT demonstra um relevante dano na saúde dos trabalhadores, não apenas pelo volume de notificações como também pelo efeito nocivo na capacidade funcional e laboral das pessoas. Esse considerável número de notificações acontece pelas extensas jornadas de trabalho, com cumprimento de horas extras, incentivados a concorrências pelo sistema de seu ganho está associado à produtividade 3 .

Além disso, o mundo do trabalho vem sofrendo renovações de forma muito rápida, onde novas exigências são impostas aos trabalhadores, novos contratos, formas de trabalhar, modos de organização do trabalho, horários, metas, produção, o que pode repercutir diretamente na saúde dos trabalhadores, causando patologias e prejudicando o processo de retorno ao trabalho. Nos últimos anos, foi possível perceber a expansão da globalização capitalista, marcada por situações de instabilidade e insegurança, podendo levar a violação dos direitos trabalhistas, motivando a precarização do trabalho e em desigualdades sociais ${ }^{5}$.

Diante disso, se achou relevante identificar a prevalência de lesões musculoesqueléticas em funcionários de empresas automotivas por meio de avaliação observacional e aplicação de questionários, visando avaliar o perfil sócio demográfico dos funcionários, correlacionando os fatores de risco que desencadeiam as lesões musculoesqueléticas e analisando a qualidade de vida desses funcionários.

\section{Metodologia}

\section{Tipo de Pesquisa}

Esse estudo foi do tipo quantitativo e qualitativo, pois contabilizou através de dados numéricos que foram transformados em estatísticas aproveitáveis, além de ter sido estudado subjetivamente as particularidades, características e experiências individuais dos participantes.

\section{Local da Pesquisa}

A Pesquisa foi realizada em 2 (duas) empresas de funilaria automotiva. 


\section{Amostra}

Por meio dos critérios de inclusão e exclusão, foram selecionados funcionários dos setores de funilaria, montagem, pintura e estoque das empresas automotivas.

\section{Critérios de Seleção dos Participantes}

Critérios de inclusão: Colaboradores técnicos devidamente registrados nas empresas de funilaria automotiva, ambos os gêneros, acima de 18 anos, alfabetizados e que trabalham há mais de 1 ano na mesma função.

Critérios de exclusão: aqueles que não estavam presentes no momento da aplicação do questionário ou o deixaram de responder da forma completa, ou mesmos os que desistiram de participar em qualquer momento durante a pesquisa.

\section{Considerações Éticas}

O protocolo desse estudo foi encaminhado ao Comitê de Ética com base na Resolução (466 / 2012) do Conselho Nacional de Saúde, e após a aprovação os voluntários foram convidados a participar da pesquisa, os quais assinaram o termo Consentimento livre e esclarecido - TCLE. Foi aprovado sob registro de CAAE 15813819.5.0000.5214.

\section{Ferramentas de Coletas de Dados}

Após assinatura do TCLE, os voluntários foram avaliados por meio de uma avaliação física e aplicado o Questionário Nórdico de Sintomas Osteomusculares (QNSO). A avaliação foi agendada previamente com cada voluntário e realizada numa sala reservada.

O QNSO é um questionário auto aplicável, composto por uma gravura do corpo humano (vista posterior) segmentado em nove regiões anatômicas, onde é possível mensurar os sintomas osteomusculares desta amostra de acordo com a análise das seguintes partes do corpo: pescoço, ombro, parte superior das costas, cotovelos, parte inferior das costas, punhos e mãos, quadril e coxas, joelhos, tornozelos e pés ${ }^{6}$.

Posteriormente, os participantes foram observados durante a execução de suas atividades do seu ambiente de trabalho, onde foram observadas as manutenções e compensações posturais e os principais movimentos durante a atividade do participante.

Vale ressaltar que todos os dados são sigilosos e os voluntários não foram identificados.

\section{Análise Estatística}

A construção das informações foi realizada utilizando-se o programa Excel, onde os registros foram armazenados até a finalização do estudo e para a apresentação dos resultados foram utilizados tabelas e gráficos. O nível de significância foi estipulado em $\mathrm{p}<0,05$.

\section{Resultados}

Dos 36 funcionários devidamente contratados pelas empresas e disponíveis para participar da pesquisa, apenas 23 assinaram o TCLE, pois 6 participantes encontravam-se de férias, 4 estavam de atestado médico, 2 haviam faltado nos dias da coleta dos dados e 1 funcionário estava de aviso prévio, não se interessando em colaborar com o trabalho. Portanto, apenas $63,9 \%$ dos voluntários participaram efetivamente da pesquisa.

O estudo evidenciou de acordo com a tabela 1, que houve predomínio do sexo masculino de $100 \%$. Já na apresentação em relação a faixa etária dos trabalhadores estudada observou-se que $2(8,69 \%)$ dos funcionários estão situados entre uma faixa etária de 18 a 29 anos, a maioria representada por $10(43,47 \%)$ estão entre 30 a 39 anos de idade, 8 participantes (34,78\%) estão entre 40 a 49 anos e apenas 3 (13,04\%) voluntários estão situados entre 50 a 59 anos de idade.

Quanto ao tempo de atividade, foram identificados 8 funcionários (34,78\%) de 1 a 10 anos exercendo a mesma função, também 8 funcionários (34,78\%) trabalhando de 11 a 24 anos no mesmo setor e apenas 7 trabalhadores $(30,43 \%)$ de 25 a 40 anos fazendo a mesma atividade. Onde foi possível ser observado que o tempo de serviço não afetou no aumento da ocorrência de lesões. 
Tabela 1. Caracterização geral da amostra estudada segundo questionário de avaliação ( $n=23)$

\begin{tabular}{|c|c|c|c|c|}
\hline VARIÁVEIS & $\mathrm{n}(\%)$ & $\bar{x}$ & \pm & Min-Máx \\
\hline \multicolumn{5}{|l|}{ Gênero } \\
\hline Masculino & $23(100)$ & & & \\
\hline Feminino & - & & & \\
\hline Idade & & 40,17 & 9,38 & 24-59 \\
\hline 18 a 29 anos & $02(8,69)$ & & & \\
\hline 30 a 39 anos & $10(43,47)$ & & & \\
\hline 40 a 49 anos & $08(34,78)$ & & & \\
\hline 50 a 59 anos & $03(13,04)$ & & & \\
\hline Tempo de Atividade & & 17,39 & 10,61 & $4-40$ \\
\hline 1 a 10 anos & $08(34,78)$ & & & \\
\hline 11 a 24 anos & $08(34,78)$ & & & \\
\hline 25 a 40 anos & $07(30,43)$ & & & \\
\hline \multicolumn{5}{|l|}{ Realiza Atividade Física } \\
\hline Sim & $15(65,22)$ & & & \\
\hline Não & $08(34,78)$ & & & \\
\hline
\end{tabular}

No gráfico 1, é possível observar que a amostra possuía um total de $7(30,43 \%)$ funcionários com o fundamental incompleto, enquanto apenas 1 (1,35\%) possuía o fundamental completo, foi analisado que 6 (26,08\%) funcionários possuíam o ensino médio incompleto, enquanto a maioria $8(34,78 \%)$ tinha o ensino médio completo e apenas $1(1,35 \%)$ já cursava o ensino superior.

Gráfico 1. Distribuição da amostra quanto à escolaridade $(n=23)$

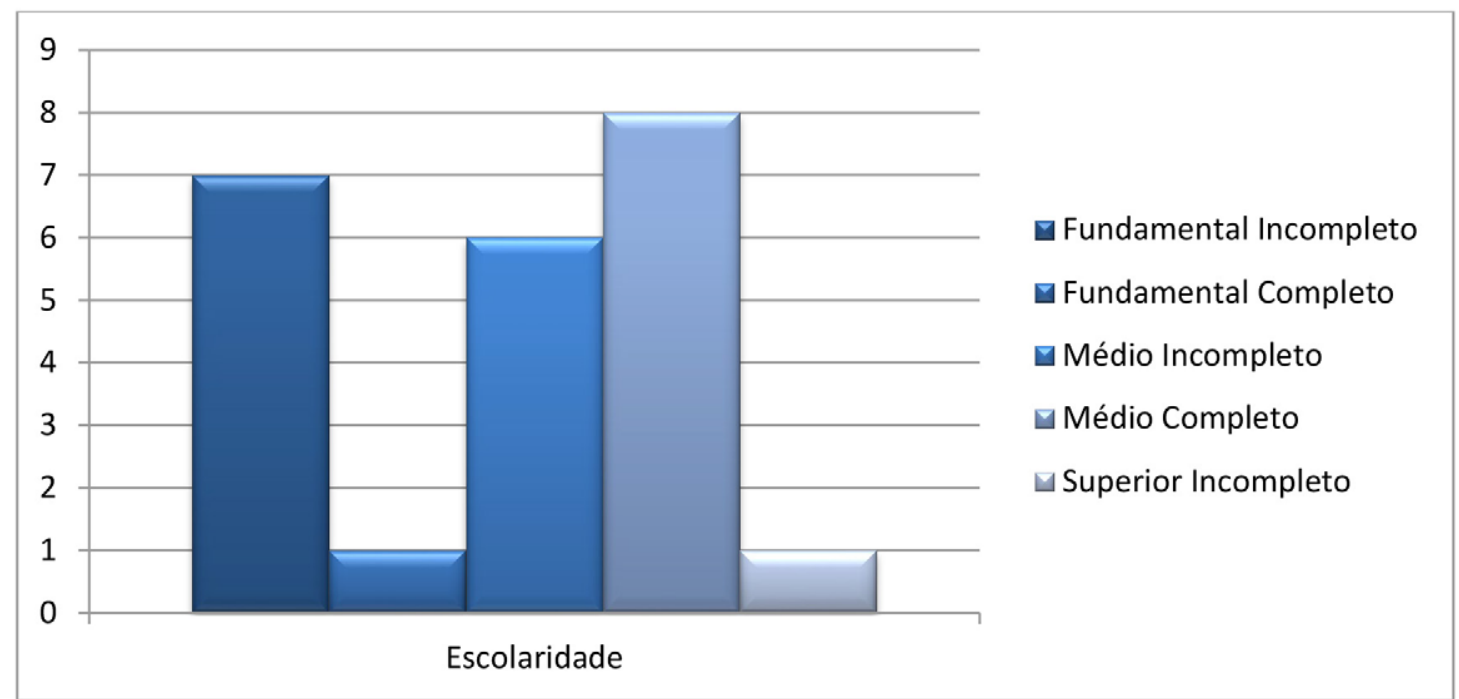


O gráfico 2 apresenta a variação da percepção subjetiva do esforço dos voluntários ao final de um dia de expediente, segundo a Escala de Borg. Com os resultados encontrados pôde-se observar que, nenhum dos funcionários optou por dizer que seu dia de trabalho é muito fácil (pontuação 6, 7 e 8) ou exaustivo (pontuação 19 e 20), apenas 1 (4,34\%) deles afirmou que era fácil (pontuação 9 e 10), 5 (21,73\%) confirmaram que seu dia ser relativamente fácil (pontuação 11 e 12), 2 (8,69\%) voluntários dizem terminar seu expediente relativamente cansados (pontuação 13 e 14), a maioria deles 13 (56,52\%) consideram cansativo (pontuação 15 e 16) e apenas $2(8,69 \%)$ relatam o dia findar muito cansativo. Quando o funcionário tem a capacidade de perceber o esforço exercido durante o seu dia de trabalho e de como o mesmo se encontra ao final do expediente, facilita no entendimento sobre a importância da prevenção da DORT.

Gráfico 2. Distribuição da amostra quanto à Percepção de esforço (n=23)

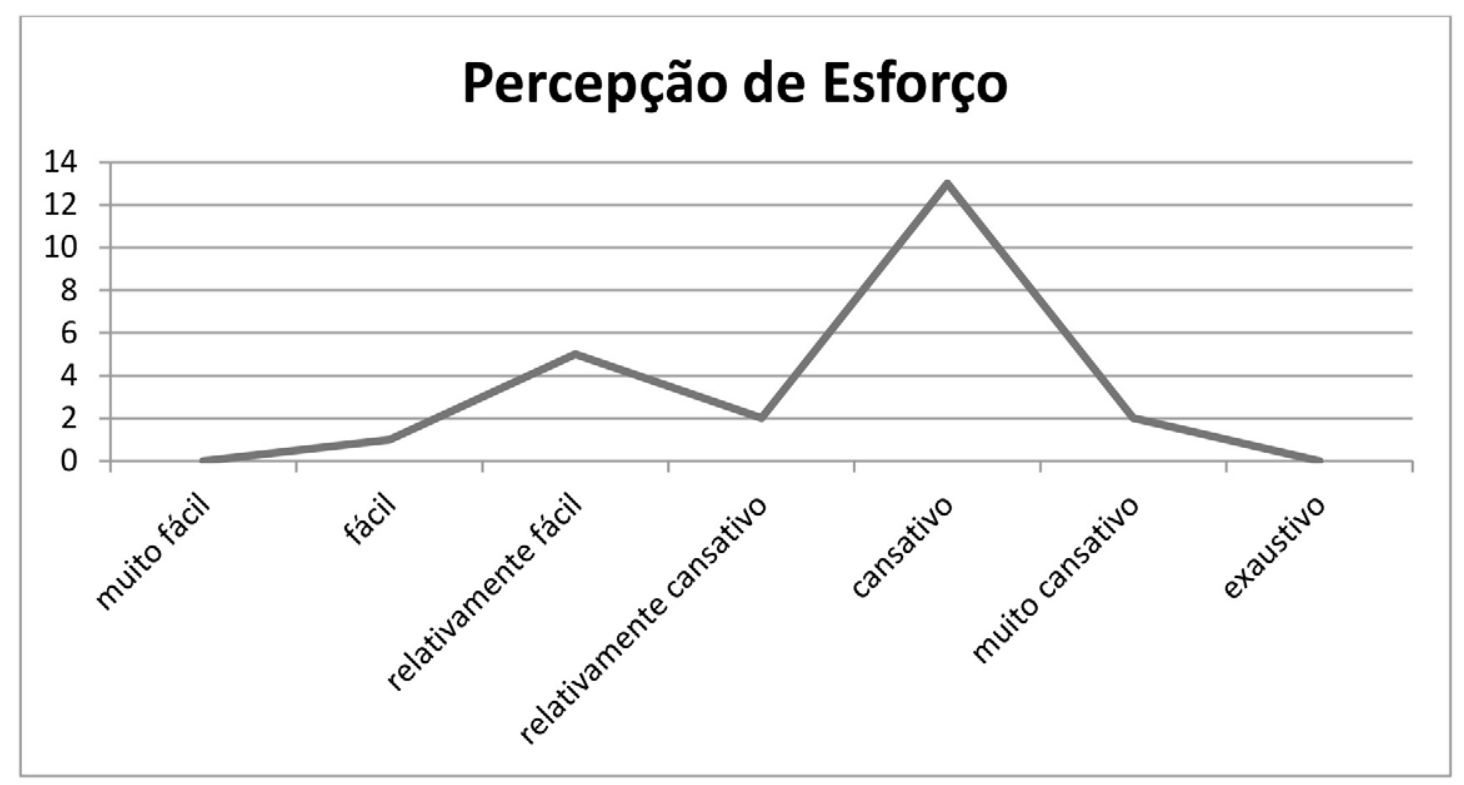

No gráfico 3 constam os resultados encontrados da amostra quanto aos relatos de dor durante e/ou após o horário de trabalho e os que não declararam dor, além de especificarem o local do incômodo. Os funcionários que afirmaram sentir dor durante horário do expediente, afirmam sentir do no ombro (2), no cotovelo (1), na coluna dorsal (1), na coluna lombar (6), no quadril (1) e no joelho (4). Após o trabalho, alguns participantes relatam dor no ombro (1), no cotovelo (1), coluna dorsal (1), coluna lombar (9), quadril (1) e joelho (6). E existem ainda os que declaram não sentir dor nem durante e nem após o dia de trabalho nas seguintes regiões do corpo: ombro (20), cotovelo (21), coluna dorsal (21), coluna lombar (8), quadril (21) e joelho (13). 


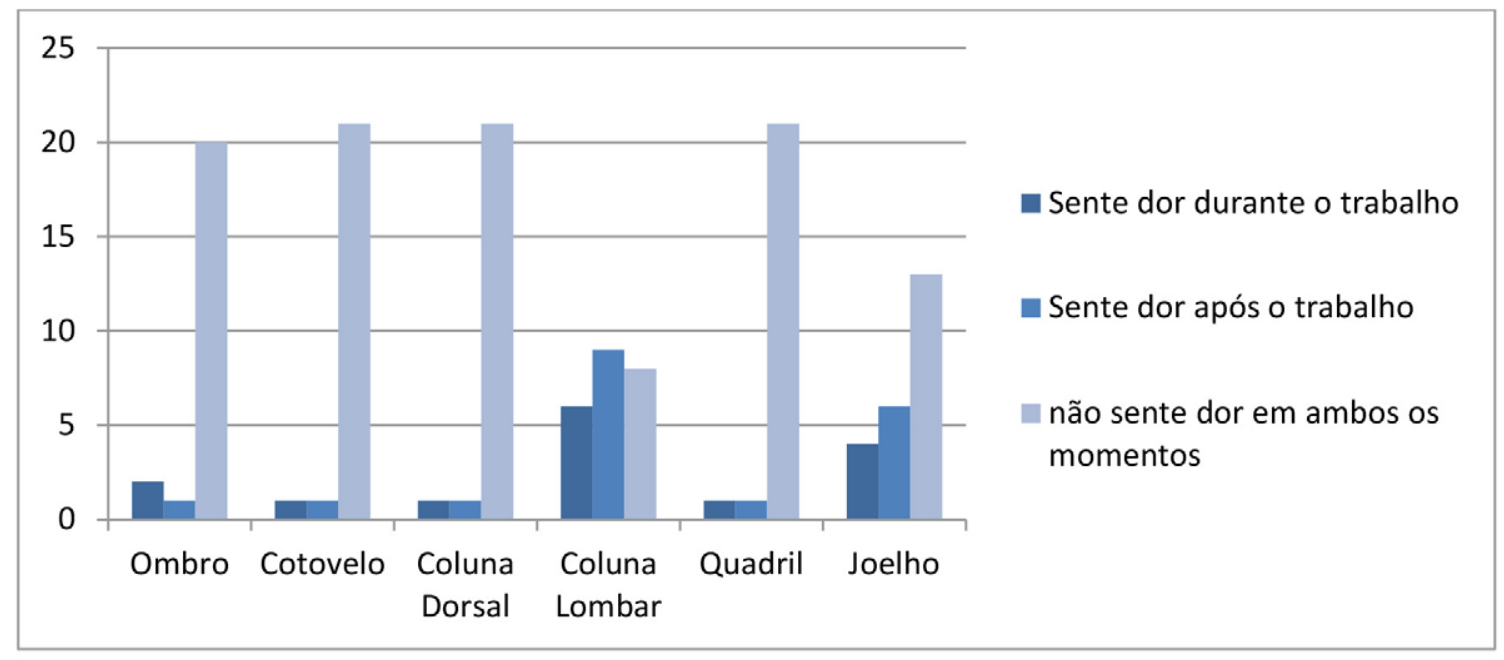

No gráfico 4 encontra-se o resultado do questionário QNSO (Questionário Nórdico de Sintomas Osteomusculares) desenvolvido com a proposta de padronizar a mensuração de relato de sintomas osteomusculares e, assim, facilitar a comparação dos resultados entre os estudos. Bastante simples e autoaplicável, porém acompanharam-se todos durante o processo de preenchimento, descartando alguma dúvida e/ou inconveniente. Primeira pergunta: Nos últimos 12 meses, você teve problemas (como dor, formigamento/ dormência), em: pescoço (3), ombro (3), parte superior das costas (9), cotovelos (2), punho/mãos (6), parte inferior das costas (14), quadril/ coxas (4), joelhos (10) e tornozelos/pés (4). Segunda pergunta: Nos últimos 12 meses, você foi impedido de realizar atividades normais (por exemplo: trabalho, atividades domésticas e de lazer, por causa dos seguintes problemas: pescoço (0), ombro (1), parte superior das costas (1), cotovelos (0), punho/mãos (0), parte inferior das costas (5), quadril/ coxas (0), joelhos (2) e tornozelos/pés (0). Terceira pergunta: Nos últimos 12 meses, você consultou algum profissional da área da saúde (médico, fisioterapeuta) por causa dessa condição: pescoço (1), ombro (0), parte superior das costas (2), cotovelos (0), punho/mãos (0), parte inferior das costas (4), quadril/ coxas (2), joelhos (3) e tornozelos/pés (1). E finalmente foi perguntado em relação aos últimos 7 dias, você teve algum problema em: pescoço (2), ombro (0), parte superior das costas (0), cotovelos (0), punho/mãos (0), parte inferior das costas (8), quadril/ coxas (1), joelhos (3) e tornozelos/pés (1).

Gráfico 4. Distribuição da amostra quanto ao QNSO (n=23)

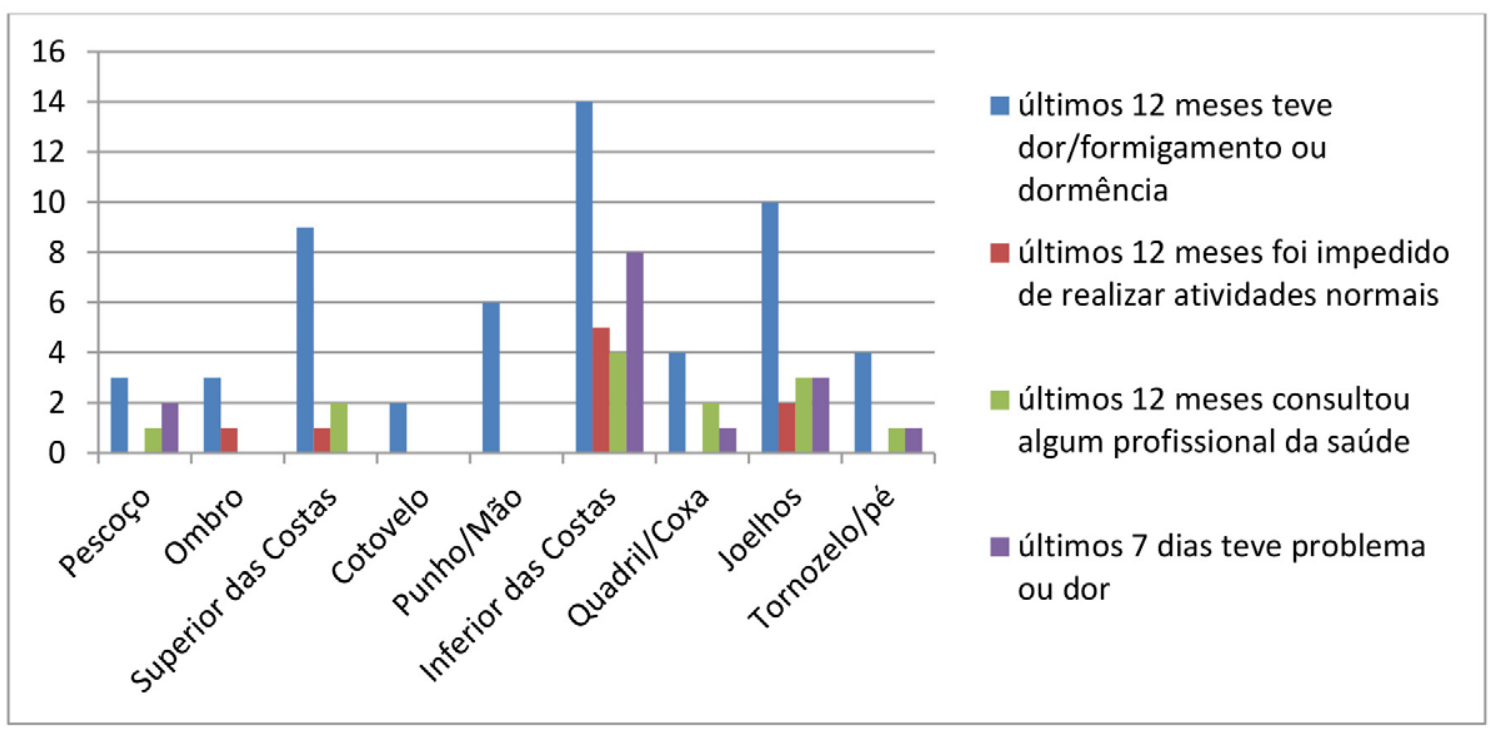




\section{Discussão}

Os resultados do presente estudo mostraram a prevalência de lesões musculoesqueléticas em parte dos funcionários participantes, ocasionadas por um conjunto de elementos que favorecem o prevalecimento dos distúrbios ocupacionais. Essas patologias, também conhecidas como LER/DORT, são motivadas por uma série de fatores gerada pelo ambiente e condições de trabalho.

As LER/DORT demonstram significantes evidências das condições de trabalho determinadas a alguns trabalhadores de diversas ocupações. Esses distúrbios são reconhecidos por multicausais, por atingir várias dimensões como psicológicas, biológicas e sociais. Por serem patologias multicausais, as LER/DORT podem ser observadas nas mais variadas profissões, cada trabalhador lesiona uma região específica de acordo com a atividade que realiza?.

Existem casos em que o adoecimento é motivado pelo uso em excesso de determinados grupos musculares, devido ao trabalho repetitivo em postura inadequada, problemas na organização do trabalho que podem estar diretamente ligadas à gestão, além de um ritmo acelerado de produção imposto aos trabaIhadores pelo capitalismo, o qual pode ser o principal agente desencadeador dessas lesões ${ }^{8}$.

Segundo Silva ${ }^{9}$, os LER / DORT apresentam uma dimensão multicausal e os fatores biomecânicos, fisiológicos e psicológicos estão entre os principais causadores. Biomecânicos envolvem postura inadequada; compressão mecânica e repetitividade. Fisiológicos incluem alterações hormonais, a estrutura óssea e articular, obesidade, estado geral de saúde, altura, entre outros. Psicológicos referem-se ao estresse, perfil psicológico individual e relações sociais. Todos esses fatores tornam o distúrbio ocupacional uma condição complexa e degradante para um indivíduo, influenciando diretamente o equilíbrio entre corpo e mente e o cenário socioeconômico e cultural do trabalhador.

Durante a coleta de dados deste projeto, foi possível ser observado que a quantidade de participantes que possuíam um menor nível de escolaridade (fundamental incompleto e fundamental) estava diretamente proporcional a prevalência de lesões na maioria das situações. Acredita-se que a pouca informação, desencadeia um menor cuidado e/ou nenhuma prevenção durante a execução de suas atividades de trabalho. E mesmo ao serem orientados em relação à postura estática e dinâmica, carga, EPI's e alguns cuidados em relação à saúde, percebeu-se certa resistência ao receber as informações. Por outro lado, os funcionários que tiveram acesso ao ensino médio ou superior, mostraram-se mais receptivos e dispostos a acatar as orientações passadas pela equipe.

De acordo com Moraes e Bastos ${ }^{8}$, dentre os aspectos sociodemográficos que estão relacionados com a saúde do trabalhador, encontra-se a escolaridade. Quanto menor a escolaridade do voluntário pesquisado, maior a percentagem de ocorrência de sintomas e diagnósticos de LER/DORT.

No estudo feito por Veigas e Almeida ${ }^{3}$, sobre distúrbios osteomusculares relacionados ao trabalho, os resultados mostraram que há tendência de crescimento dos índices de afastamento por LER/DORT e em relação ao nível de escolaridade, foi encontrada uma maior prevalência de casos nos indivíduos com ensino fundamental incompleto, observando-se também que os indivíduos com vínculo empregatício formal obtiveram maior acometimento.

Segundo Paula et al. ${ }^{10}$, foi encontrado em seus resultados uma influência negativa da baixa escolaridade na qualidade de vida dos indivíduos com afecções osteomusculares, mas com efeito negativo mais marcante na dimensão física, apresentando menor percepção sobre a saúde, o que corrobora com as pesquisas dos autores citados anteriormente.

É importante destacar que a região do corpo mais acometida durante o presente estudo foi a coluna lombar. Na aplicação do Questionário Nórdico de Sintomas Osteomusculares houve relato de 14 funcionários (60\%) de um total de 23 pesquisados, que nos últimos 12 meses tiveram problemas, como dor, formigamento ou dormência na região inferior das costas, ou seja, região lombar. Além disso, durante a avaliação e aplicação dos questionários de avaliação e sociodemográfico foi possível observar que a queixa de quadro álgico dos funcionários existe mesmo antes deles iniciarem suas atividades diárias, permanecem durante o expediente e na maioria das vezes se agravam ao final do dia. 
A coluna vertebral é a parte do corpo humano com uma maior sobrecarga motora, devido a isso que ocorrem as alterações posturais e onde acontece a maioria das disfunções musculoesqueléticas e problemas crônicos de coluna (PCC), como as mais frequentes podem ser citadas as cervicalgias, lombalgias, dores torácicas e ciáticas, espondiloses, radiculopatias e transtornos dos discos intervertebrais ${ }^{11}$.

De acordo com Santos et al. ${ }^{12}$, as dores de coluna são uma experiência bastante frequente em trabalhadores adultos, apontando uma prevalência de aproximadamente 15 a $30 \%$ e sendo a maior causa do comprometimento da capacidade produtiva, problemas socioeconômicos e perda de qualidade de vida do indivíduo. Entre os diagnósticos de dor nas costas que geraram as aposentadorias por invalidez, os mais recorrentes foram dorsalgia e dor lombar baixa. Além disso, relata que a lombalgia afeta $10 \%$ da população mundial, em intensidades de leve a muito grave.

Concomitante aos questionários foi aplicada também a Escala de Borg, considerada de suma importância, pois se verificou o relatado dos próprios participantes através de sua percepção subjetiva do esforço, sendo possível perceber o grau de condicionamento dos indivíduos após o dia de trabalho.

A possibilidade de utilização das escalas de Percepção de Esforço é bastante variada, podendo estas ser utilizadas em testes de esforço, na prescrição de exercícios, em situações clínicas e em atividades ocupacionais ${ }^{13}$.

De acordo com Silva et al. ${ }^{9}$, o esforço percebido é um indicador válido e confiável para monitorar a tolerância de um indivíduo ao exercício. Usada comumente durante a realização de testes de esforço progressivo, associa-se com a frequência cardíaca e com a intensidade do exercício. As escalas de percepção de esforço foram criadas com o objetivo de estabelecer relações entre a percepção de esforço e os dados de carga externa, ou de estresse fisiológico.

\section{Conclusão}

Em geral, este estudo buscou demonstrar dados para discutir a noção de LER/DORT, seus resultados apontaram para a região da coluna lombar como sendo a de maior intensidade de distúrbios musculoesqueléticos relacionados ao trabalho entre o grupo de trabalhadores pesquisados. Foi observado que não há uma relação linear entre sintomas osteomusculares, avaliação hemodinâmica, idade, função exercida e tempo de serviço, quando controlada a condição de saúde através do auto relato de diagnóstico.

Por outro lado, a baixa escolarização esteve associada com o aumento da probabilidade de diagnóstico, na amostra estudada. Esse fator se mostrou diretamente proporcional a qualificação do trabalhador e, consequentemente, com a ocupação de cargos menos repetitivos com maiores possibilidades de promoção e recompensa. As LER/DORT ainda permanecem como um dos maiores problemas de saúde pública relacionados à incapacitação ao trabalho. As empresas precisam colaborar, no sentido de promover ações, investindo em profissionais capacitados que orientem corretamente seus funcionários, que estimulem a prevenção das dores e desconfortos musculoesqueléticos, além de favorecer a vigilância na construção de um ambiente saudável no contexto laboral, regularizando as pausas durante o expediente e incentivando o uso de EPIs.

Este estudo é de grande importância devido aos benefícios que poderá trazer se bem aproveitado. Poderá guiar novas pesquisas na área da Fisioterapia do trabalho de acordo com a epidemiologia encontrada e contribuir para o aumento das possibilidades de prevenção dentro das empresas. No caso dos colaboradores, o benefício será a melhora da consciência postural, diminuição da sobrecarga biomecânica nas estruturas osteomusculares, promovendo menor gasto energético, prevenindo doenças ocupacionais e favorecendo para que haja uma diminuição de afastamentos do trabalho. 


\section{Contribuição dos autores}

Adad RBSF participou da concepção, delineamento, busca, coleta e análise estatística dos dados da pesquisa, interpretação dos resultados e redação e do artigo científico. Silva DH participou da coleta de dados da pesquisa. Sousa IM participou do delineamento, análise estatística dos dados da pesquisa, interpretação dos resultados e redação.

\section{Conflitos de interesses}

Nenhum conflito financeiro, legal ou político envolvendo terceiros (governo, empresas e fundações privadas, etc.) foi declarado para nenhum aspecto do trabalho submetido (incluindo, mas não se limitando a subvenções e financiamentos, participação em conselho consultivo, desenho de estudo, preparação de manuscrito, análise estatística, etc.).

\section{Referências}

1. Fernandes RCP, Assunção AA, Silvany Neto AM, Carvalho FM. Distúrbios musculoesqueléticos em trabalhadores de fábricas de plásticos. Rev Bras Epidemiol. 2010;13(1):11-20. doi: 10.1590/ S1415-790X2010000100002

2. Lourinho MG, Negreiros GR, Almeida LB, Vieira ER, Quemelo PRV. Riscos de lesão musculoesquelética em diferentes setores de uma empresa calçadista. Fisioterapia e Pesquisa. 2011;18(3):2527. doi: $10.1590 / 51809-29502011000300009$

3. Viegas LRT, Almeida MMC. Perfil epidemiológico dos casos de LER/DORT entre trabalhadores da indústria no Brasil no período de 2007 a 2013. Rev Bras Saúde Ocup. 2016;41:e22. doi: 10.1590/2317-6369000130615

4. Gibson SK, Paudyal V, Klein S, Stewart D. Saúde, autocuidado e força de trabalho offshore - oportunidades para intervenções de mudança de comportamento, um levantamento epidemiológico. Saúde Rural e Remota. 2018;18(2):4319. doi: 10.22605/RRH4319

5. Pestana BM, Valença JBM, Graeser AEM, Alencar MCB. O retorno ao trabalho de edições acometidas por LER / DORT. Cadernos Brasileiros de Terapia Ocupacional. 2017;25(4):735-742. doi: 10.4322/2526-8910.ctoAO0843

6. Santos RR. Desordens Osteomusculares em alunos de Odontologia. Desordens Osteomusculares em escolares de Odontologia [tese]. Araçatuba: Universidade Estadual Paulista Júlio de Mesquita Filho; 2015.

7. Dale AP, Dias MDA. A 'extravagância' de trabalhar doente: o corpo no trabalho em indivíduos com diagnóstico de LER/DORT. Trab Educ Saúde. 2018;16(1):263-282. doi: 10.1590/1981-7746sol00106
8. Moraes PWT, Bastos AVB. Os Sintomas de LER/DORT: um Estudo Comparativo entre Bancários com e sem Diagnóstico. Psicol Cienc Prof. 2017;37(3):624-637. doi: 10.1590/1982$\underline{3703001862016}$

9. Silva MB, Picasso CLM, Rosito MP. Perfil epidemiológico de trabalhadores com distúrbios osteomusculares de uma empresa de supermercado. Fisioter Mov. 2015;28(3):573-581. doi: 10.1590/0103-5150.028.003.A016

10. Paula EA, Buschinelli JT, Maeno M, Costa RF. Qualidade de vida de trabalhadores com LER/DORT e lombalgia ocupacional atendidos no CEREST de Guarulhos, São Paulo. Rev Bras Saude Ocup. 2016;41:e19. doi: 10.1590/2317-6369000120115

11. Teixeira EP, Mussi RFF, Petroski El, Munaro HLR, Figueiredo ACMG. Problema crônico de coluna/dor nas costas em população quilombolas de região baiana, nordeste brasileiro. Fisioter Pesqui. 2019;26(1):85-90. doi: 10.1590/1809-2950/18024126012019

12. Santos VM, Santos JW, Alsina OLS, Monteiro LF. Aplicação do Questionário Nórdico Musculoesquelético para estimar a prevalência de distúrbios osteomusculares relacionados ao trabalho em operárias sob pressão temporal. In: XXXV Encontro Nacional de Engenharia de Produção. Perspectivas Globais para Engenharia de Produção. ABEPRO. 2015; Fortaleza - CE. P. 1-15.

13. Tiggemann CL, Pinto RS, Kruel LFM. A Percepção de Esforço no Treinamento de Força. Rev Bras Med Esporte. 2010;16(4):1-9. doi: 10.1590/S1517-86922010000400014 